\title{
ALTERAÇÕES DA MEDULA ÓSSEA E A IMPORTANCIA DO MIELOGRAMA NO DIAGNÓSTICO DA EHRLICHIOSE MONOCÍTICA CANINA - REVISÃO
}

\author{
Marília Salgado Caxito ${ }^{1}$ \\ Fernanda Panseri Rodrigues ${ }^{2}$ \\ Isis Indaiara Gonçalves Granjeiro Taques ${ }^{3}$ \\ Daniel Moura de Aguiar ${ }^{4}$ \\ Regina Kiomi Takahira ${ }^{5}$ \\ Antônio Carlos Paes ${ }^{6}$
}

\begin{abstract}
RESUMO
A Ehrlichiose Monocítica Canina (EMC) é uma doença multissistêmica e de alta incidência. Contudo, a patogenia da enfermidade ainda não está totalmente esclarecida. Infiltrações plasmocitárias e linfoplasmocitárias são observadas em grande parte dos órgãos de animais acometidos, inclusive na medula óssea. Esses infiltrados sugerem que a maioria das lesões patológicas identificadas na fase crônica pode ser consequência do processo inflamatório originado no início da infecção. Este trabalho tem por objetivo destacar a importância da avaliação medular de cães com EMC. A maior compreensão das alterações medulares na fase aguda poderia esclarecer a origem das alterações observadas na fase crônica. Mais estudos são necessários para verificar se a patogenia da EMC está relacionada apenas a processos imunomediados ou se também há agressões diretas de Ehrlichia canis às células precursoras. Elucidar os mecanismos fisiopatogênicos de E. canis poderia melhorar a terapêutica instituída como também o prognóstico de animais gravemente acometidos.
\end{abstract}

Palavras-chave: Ehrlichia canis, mielograma, hematopoiese, células precursoras, processo imunomediado.

\section{BONE MARROW CHANGES AND THE IMPORTANCE OF THE MYELOGRAM IN DIAGNOSING CANINE MONOCYTICS EHRLICHIOSIS - A REVIEW}

\begin{abstract}
Canine Monocytic Ehrlichiosis (CME) is a multisystemic disease with high incidence among dogs. However, its pathogenesis has not been fully elucidated. Plasma cells and lymphoplasmacytic infiltrates are observed in most organs of infected animals, including bone marrow. These infiltrates suggest that most of the pathological lesions identified in the chronic phase may be a consequence of the inflammatory process initiated at the beginning of the infection. This work aims to highlight the importance of the bone marrow evaluation of dogs with CME. A better understanding of the medullary changes in the acute phase could help clarifying the origin of clinical signs observed in the chronic phase. More studies are needed to verify whether the pathogenesis of CME is related to either the immune-mediated processes or the direct aggressions of Ehrlichia canis in precursor cells. Understanding the pathophysiological mechanisms of E. canis will improvement both current therapeutic strategies as well as the prognosis of severely affected animals.

\footnotetext{
${ }^{1}$ Mestranda em Medicina Veterinária, FMVZ, UNESP - Botucatu, SP. Correspondência.

${ }_{2}^{2}$ Médica Veterinária Residente do Laboratório Clínico Veterinário, Departamento de Clínica Veterinária, FMVZ, UNESP - Botucatu, SP

${ }^{3}$ Doutoranda em Ciências Veterinárias, FAMEVZ, Universidade Federal do Mato Grosso - Cuiabá, MT.

${ }^{4}$ Docente, Departamento de Clínica Médica Veterinária, FAMEVZ, Universidade Federal do Mato Grosso, Cuiabá, MT.

${ }^{5}$ Docente, Departamento de Clínica Veterinária, FMVZ, UNESP - Botucatu, SP.
}

${ }^{6}$ Docente, Departamento de Higiene Veterinária e Saúde Pública, FMVZ, UNESP - Botucatu, SP
\end{abstract}

Caxito MS, Rodrigues FP, Taques IIGG, Aguiar DM. et al. Alterações da medula óssea e a importância do mielograma no diagnóstico da ehrlichiose monocítica canina - Revisão. Vet. e Zootec. 2018 mar.; 25(1): 061066. 
Keywords: Ehrlichia canis, myelogram, hematopoiesis, precursor cells, immune-mediated process.

\title{
ALTERACIONES EN LA MÉDULA ÓSEA Y LA IMPORTANCIA DEL MILOGRAMA EN EL DIAGNOSTICO DE EHRLICHIOSIS MONOCITICA CANINA - REVISIÓN
}

\begin{abstract}
RESUMÉN
La Ehrlichiosis Monocítica Canina (EMC) es una enfermedad multisistémica de alta incidencia. Sin embargo, su patogénesis de la enfermedad aún no ha sido elucidada. Lãs infiltraciones plasmocitarias y linfoplasmocitarias se observan en la mayoría de los órganos de animales afectados, incluyendo la médula ósea. Estas infiltraciones sugieren que la mayoría de las lesiones patológicas identificadas en la fase crónica son uma posible consecuencia del proceso inflamatorio iniciado a comienzos de la infección. Este estudio propone destacar la importância de evaluar la médula en perros afectados por EMC. Una mejor comprension de las cambios medulares en la fase aguda podría aclarar el origen de los signos clínicos observados en la fase crónica. Esta revisión concluye la necesidad de um mayor numero de estudios para verificar si la patogénesis de EMC se relaciona únicamente con procesos autoinmunes o con ataques directos de Ehrlichia canis a las células precursoras. Uma mejor comprension de los mecanismos fisiopatológicos de E. canis podría permitir un mejoramiento tanto del enfoque terapêutico como del pronóstico de los animales gravemente afectados.
\end{abstract}

Palabras-clave: Ehrlichia canis, mielograma, hematopoiese, células precursoras, proceso autoinmune.

\section{INTRODUÇÃO}

A Ehrlichiose Monocítica Canina (EMC) é causada por bactérias gram-negativas, pleomórficas pertencentes ao gênero Ehrlichia, das quais a Ehrlichia canis (E. canis) é a espécie que se destaca no Brasil (1). Estudos epidemiológicos em diversas regiões do país demonstraram que cerca de $20 \%$ dos cães apresentam a doença (2). Embora a infecção em áreas rurais esteja presente, cães que residem em ambiente urbanizado são os mais acometidos já que populações do carrapato vetor, Rhipicephalus sanguineus, são mais abundantes nessas regiões (3).

A doença nos cães pode ser aguda, subclínica ou crônica. Contudo, a fase crônica revela alta mortalidade mesmo com antibioticoterapia instituída. As razões para o desenvolvimento desta fase não é elucidado, contudo, nota-se forte influência do sistema imunológico. Hipergamaglobulinemia, acúmulo de células linfóides e plasmocitose generalizada são alterações comumente observadas nos cães infectados. Estes achados comuns em cães portadores de EMC indica resposta humoral exacerbada associada à patogênese da enfermidade (4).

Alterações em sangue periférico podem ser observadas em qualquer fase da afecção e não são suficientes para determinar a fase da doença. A avaliação medular pode auxiliar não apenas na determinação correta da fase da infecção como identificar melhor as desordens hematológicas e, em alguns casos, adiantar-se a essas alterações (5).

Caxito MS, Rodrigues FP, Taques IIGG, Aguiar DM. et al. Alterações da medula óssea e a importância do mielograma no diagnóstico da ehrlichiose monocítica canina - Revisão. Vet. e Zootec. 2018 mar.; 25(1): 061066. 


\section{REVISÃO DE LITERATURA}

\section{Etiopatogenia e manifestações clínicas e hematológicas}

Por ser um parasita intracelular obrigatório, o agente etiológico invade células do sistema fagocítico mononuclear e, após multiplicar-se em macrófagos por fissão binária, se dissemina pelo organismo do hospedeiro. $\mathrm{O}$ vetor necessita de pouco tempo para transmitir a infecção. Estudos recentes comprovaram que apenas 3 horas de fixação são suficientes para os animais parasitados se tornarem infectados (6).

Os principais sinais clínicos da EMC são inespecíficos, tais como apatia, anorexia, linfadenomegalia, evidente hepatoesplenomegalia, perda de peso, descargas nasais e oculares e febre. Alterações no sangue periférico podem ser observadas entre 5 e 18 dias pós-infecção (PI). Em média, 10 dias PI já são suficientes para o estabelecimento da trombocitopenia, que é a principal característica da EMC (4). Um dos fatores que contribui para essa diminuição plaquetária é a destruição mediada por células do sistema imune do hospedeiro. Em infecções agudas naturais e experimentais os anticorpos ligados a plaquetas e anticorpos antiplaquetários têm demonstrado papel importante na patogenia da doença (7). A anemia também é frequentemente observada na EMC e está relacionada à supressão da atividade eritropoiética. Citocinas inflamatórias (IL-1, INF- $\gamma$ e TNF- $\alpha$ ) são liberadas pelas células infectadas causando anemia da inflamação (8).

A intensidade das alterações varia de acordo com a fase da infecção (7). Contudo, cães que evoluem para forma crônica também podem apresentar, além dos sinais supracitados, diáteses hemorrágicas. No hemograma desses animais, se observa grave pancitopenia (marcada trombocitopenia, anemia arregenerativa e leucopenia intensa). A alta mortalidade nesta fase é resultante da síndrome hemorrágica e/ou infecções secundárias (4). O diagnóstico precoce com a identificação correta da fase da infecção e rápida instituição do tratamento são fundamentais para evitar alta letalidade nos cães.

A diminuição da contagem plaquetária ocorre em todas as fases da doença, utilizado como indicador clínico de suspeita de EMC. O diagnóstico definitivo é firmado pela visualização de agrupamentos intracitoplasmáticos (mórulas) nos monócitos circulantes em esfregaços sanguíneos, presença de altos títulos de anticorpos para E. canis, detecção do DNA da bactéria pela PCR ou, ainda, pelo isolamento do agente em cultivos celulares (7).

Apesar de normalmente não serem exames solicitados nos casos de EMC, aspirados ou biópsias medulares podem auxiliar no acompanhamento e principalmente no prognóstico de cães acometidos pela EMC. O mielograma consiste na identificação de mórulas de E. canis, exclusão de outras causas de pancitopenia ou desordens hematológicas e avalia precursores hematopoiéticos. Além disso, a punção medular é necessária na determinação da fase da doença e com isso pode-se eleger o melhor tratamento para os animais doentes. Evidências sugerem que mecanismos no início da infecção podem ser responsáveis por muitas lesões patológicas observadas na fase crônica. Estudos para identificar alterações medulares da EMC, principalmente na fase aguda, podem esclarecer alterações irreversíveis da fase crônica e elucidar a patogenia da EMC.

\section{Alterações medulares na EMC aguda}

A avaliação de medula óssea é indicada nos casos de bicitopenias ou pancitopenias persistentes, anemias arregenerativas, desordens mieloproliferativas, febre de origem desconhecida ou a combinação de dois ou mais dos fatores citados (5). Considerado como importante método de diagnóstico nas doenças infecciosas, o mielograma auxilia também no 
prognóstico da EMC uma vez que além de diferenciar outras causas de pancitopenia possibilita, também, diagnosticar desordens hematológicas primárias, verificar possíveis áreas de hematopoiese ativas e avaliar os precursores eritróides, mielóides e megacariocíticos.

As alterações medulares de cães com EMC nas diferentes fases são bem distintas. Acredita-se que essas alterações podem ser causadas pela supressão hematopoiética secundária à infecção por Ehrlichia sp. A intensidade da supressão e/ou destruição da medula óssea está associada à produção deficiente de um ou mais elementos sanguíneos, dependendo da fase da doença. O comprometimento medular indica agressão não só ao estroma vascular, mas também às células precursoras. Como mórulas de E. canis podem ser encontradas em sangue periférico e em aspirados medulares a partir de 15 dias PI (9), uma hipótese seria de que as células-tronco sejam infectadas por E. canis resultando na falha do metabolismo dessas células e, consequentemente, na proliferação celular $(4,9,10)$.

Estudos citológicos de medula óssea em cães experimentalmente infectados apresentando EMC na fase aguda revelaram aumento inicial na proporção mielóide:eritróide (M:E) e na concentração média de megacariócitos a partir de 1 dia até 2 meses PI. O aumento da relação M:E provavelmente está associado à hipoplasia eritróide, devido às citocinas inflamatórias (IL-1, IL-6, INF- $\gamma$ e TNF- $\alpha$ ) que alteram a cinética do ferro e a disponibilidade desse íon para síntese de hemoglobina (11). Nota-se ainda que na fase aguda da enfermidade, a destruição celular é principalmente de origem periférica. Para corrigir as citopenias periféricas a medula óssea aumenta sua atividade de replicação celular e, portanto, a hiperplasia medular é facilmente compreendida (4). Até o momento, não está comprovado que anticorpos antiplaquetários também exerçam ação sobre os megacariócitos, uma vez que o curto período de vida das plaquetas na circulação sinaliza a disfunção medular. Contudo, o aumento do volume plaquetário médio (VPM) resulta da presença de macroplaquetas no sangue periférico e é interpretado como resposta megacariocítica adequada (9).

Novos estudos têm investigado a ação das citocinas na patogênese da supressão medular. Pertencentes a uma família especializada de citocinas, as quimiocinas são proteínas pequenas que atuam como potentes mediadores da inflamação e quimiotaxia de subpopulações específicas de leucócitos. As quimiocinas são essenciais para promover a resposta do hospedeiro diante da infecção e estão subdivididas em subfamílias: CXC (atuam sobre neutrófilos), CC (agem sobre eosinófilos, células natural killer, linfócitos e monócitos), C e CX3C, das quais as duas últimas classes são menos descritas (9). A secreção dessas quimiocinas está relacionada à presença de inclusões intracitoplasmáticas de Ehrlichia. Estudos in vitro com células medulares infectadas com Anaplasma phagocytophilum (agente infeccioso intimamente relacionado com E. canis) mostraram aumentos significativos na produção de quimiocinas da subfamília CC: Proteína Inflamatória de Macrófagos (MIP-1 $\alpha$ ou CCL3 e MIP-1 $\beta$ ou CCL4), Proteína Quimiotática Monocítica (MCP-1 ou CCL2) e RANTES (CCL5) e da subfamília CXC: IL-8 (CXCL8) (12). Enquanto baixas concentrações de MIP-1 $\alpha$ e IL-8 agem sinergicamente regulando a hematopoiese, altas concentrações de MIP-1 $\alpha$, IL-8 e MCP-1 suprimem a proliferação de células precursoras. Incapaz de compensar as anemias arregenerativas discretas na doença aguda, a medula óssea demonstra mau funcionamento da eritropoiese em cães portadores de $\operatorname{EMC}(9,12)$.

\section{Alterações medulares na EMC crônica}

Alguns cães convalescentes da doença crônica podem apresentar normocelularidade no mielograma sugerindo supressão medular moderada. Entretanto, a fase crônica caracteriza-se por hipocelularidade medular acentuada dos três tipos celulares (eritróide, mielóide e megacariocítica), não raro evoluindo para falência medular (Figura 1). Animais acometidos pela doença crônica grave e que evoluem para óbito mesmo depois de instituído o tratamento

Caxito MS, Rodrigues FP, Taques IIGG, Aguiar DM. et al. Alterações da medula óssea e a importância do mielograma no diagnóstico da ehrlichiose monocítica canina - Revisão. Vet. e Zootec. 2018 mar.; 25(1): 061066. 
comumente apresentam aplasia medular persistente observada após a hipergamaglobulinemia. A terapia imunossupressora instituída quando a concentração de anticorpos atinge altos títulos associada ao tratamento específico da EMC tem demonstrado resultados satisfatórios sugerindo base imunomediada da doença (9).

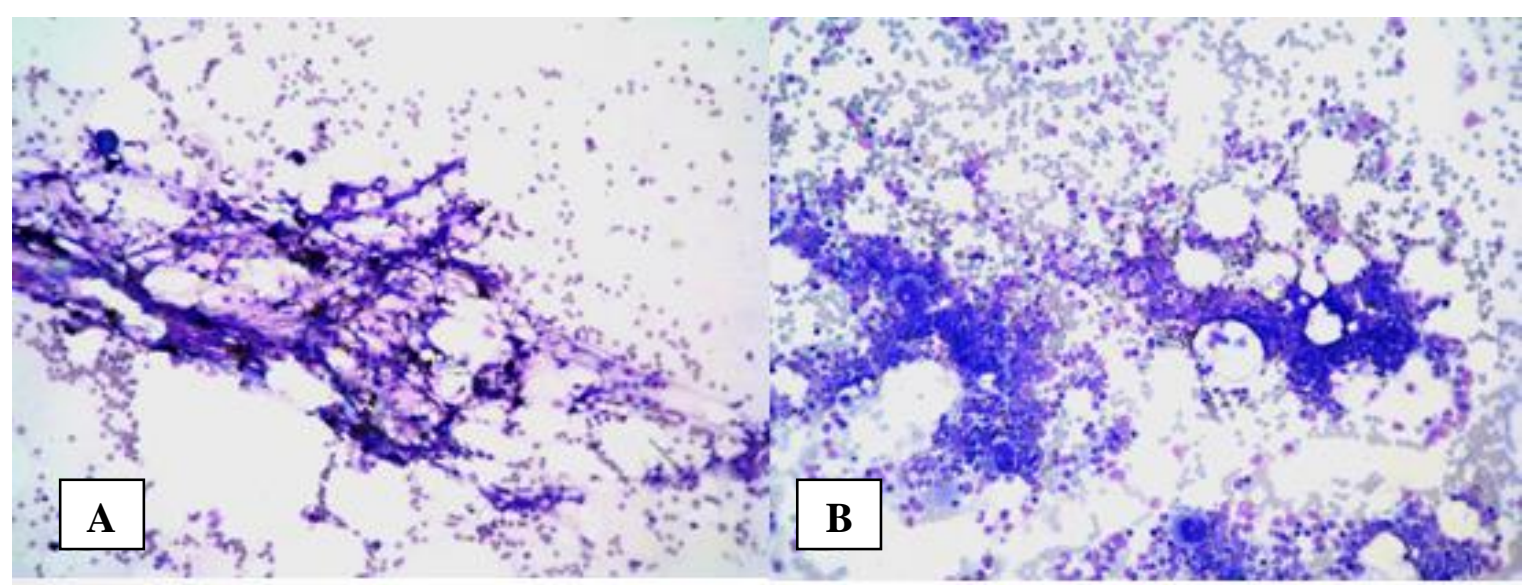

Figura 1- A: Aplasia medular de origem infecciosa (PCR positiva para E. canis) de um canino, SRD, fêmea de 3 anos. B: Medula hematopoieticamente ativa de um canino Poodle, fêmea de 5 anos. Fonte: Laboratório Clínico Veterinário da FMVZ - UNESP Botucatu-SP. Coloração panótico (aumento de 100x)

A patogenia da hipoplasia medular na erliquiose crônica ainda é desconhecida, mas presume-se que a resposta imunológica do organismo suprima a hematopoiese (13). A hipoplasia/aplasia de medula em infecções por E. canis em cães pode ainda estar relacionada aos casos de mielonecrose, tanto por danos diretos às células hematopoiéticas quanto por danos na microcirculação das artérias nutrícias (5). Além disso, o processo inflamatório, danos vasculares e necrose, ou secundários à anemia imunomediada, são fatores que podem levar a quadros de mielofitise como consequência da proliferação de fibroblastos. O tecido fibroso que invade a medula óssea compete com as células hematopoiéticas pelo espaço e nutrientes afetando todos os tipos celulares. Citocinas inflamatórias produzidas em doenças imunomediadas primárias ou secundárias a enfermidades infecciosas podem desencadear síndrome hemofagocítica caracterizada por esquizócitos e monócitos ativados no sangue periférico e pelo aumento de macrófagos fagocitando células precursoras sanguíneas na medula óssea e em outros órgãos linfóides como fígado, linfonodos e/ou baço (5).

\section{Considerações finais}

As alterações citomorfológicas da medula óssea de cães com EMC são pouco estudadas. Contudo, o mielograma revela sua importância como exame complementar principalmente no prognóstico da EMC uma vez que, além de diferenciar outras causas de bicitopenias/pancitopenias, é possível a partir deste exame se obter informações sobre desordens hematológicas, verificar possíveis áreas de hematopoiese ativas e avaliar os precursores eritróides, mielóides, linfóides e megacariocíticos.

\section{REFERÊNCIAS}

1 Vieira RFC, Biondo AW, Guimarães AMS, Santos AP, Dutra LH, Diniz PPVP, et al. Ehrlichiosis in Brazil. Rev Bras Parasitol Vet. 2011;20(1):1-12.

Caxito MS, Rodrigues FP, Taques IIGG, Aguiar DM. et al. Alterações da medula óssea e a importância do mielograma no diagnóstico da ehrlichiose monocítica canina - Revisão. Vet. e Zootec. 2018 mar.; 25(1): 061066. 
2 Labarthe N, Pereira MC, Barbarini O, Mckee W, Coimbra CA, Hoskins J. Serologic prevalence of Dirofilaria immitis, Ehrlichia canis and Borrelia burgdorferi infection in Brazil. Vet Ther. 2003;4(1):67-75.

3 Aguiar CLG, Pinto DM, Pappen FG, Filho NAC, Santos TRB, Farias NAR. Parâmetros da fase de vida livre de Rhipicephalus sanguineus (Latreille, 1806) (Acari: Ixodidae): adaptado ao clima subtropical. Arq Inst Biol. 2013;80(4):375-80.

4 Waner T, Harrus S. Canine monocytic ehrlichiosis - from pathology to clinical manifestations. Isr J Vet Med. 2013;68(1):12-8.

5 Moraes LF, Takahira RK. Aplasia medular em cães. Rev Cienc Agrovet. 2010;9(1):99108.

6 Sainz A, Roura X, Miró G, Estrada-Peña A, Kohn B, Harrus S, et al. Guideline for veterinary practitioners on canine ehrlichiosis and anaplasmosis in Europe. Parasit Vectors. 2015;8:75.

7 Harrus S, Waner T, Aizenberg I, Foley JE, Poland AM, Bark H. Amplification of ehrlichial DNA from dogs 34 months after infection with Ehrlichia canis. J Clin Microbiol. 1998;36(1):73-6.

8 Harrus S, Waner T, Neer TM. Ehrlichia canis infection. In: Greene CE. Infectious diseases of the dog and cat. 4th ed. St. Louis: Elsevier; 2015. p.227-56.

9 Waner T. Hematopathological changes in dogs infected with Ehrlichia canis. Isr J Vet Med. 2008;63(1):1-8.

10 Moreira SM, Machado R, Passos LF. Detection of Ehrlichia canis in bone marrow aspirates of experimentally infected dogs. Cienc Rural. 2005;35(4):958-60.

11 Harvey JW. Veterinary hematology: a diagnostic guide and color atlas. St. Louis: Elsevier; 2012.

12 Rikihisa Y. Mechanisms of obligatory intracellular infection with Anaplasma phagocytophilum. Clin Microbiol Rev. 2011;24(3):469-89.

13 Harrus S, Waner T, Weiss DJ, Keysary A, Bark H. Kinetics of serum antiplatelet antibodies in experimental acute canine ehrlichiosis. Vet Immunol Immunopathol. 1996;51(1-2):13-20.

Recebido em: Aceito em: 